Economy]. Vestnik AGTU. Seriya: Ekonomika [Bulletin of ASTU. Series: Economics], no. 2, pp. 7-15.

24 Panchenko S.V., Dy`kan` V.L., Shramenko O.V., Polyakova O.M., Utkina Yu.M. (2016) Teorety`chni osnovy` organizaciyi pidpry`yemny`cz koyi diyal'nosti [Theoretical bases of the organization of business activity]. Pidpry yemny cztvo
[Business]. Xarkiv: UkrDUZT. (in Ukrainian) 25 Panchenko S.V., Dy`kan` V.L., Shramenko O.V., Polyakova O.M., Utkina Yu.M. (2016) Realizaciya pidpry`yemny`cz`koyi diyal’nosti u suchasny`x ry`nkovy`x umovax [Implementation of entrepreneurial activity in modern market conditions]. Pidpry'yemny cztvo [Business]. Xarkiv: UkrDUZT. (in Ukrainian)

\title{
ПІДХОДИ ВИКОРИСТАННЯ СИСТЕМ ПІДТРИМКИ ПРИЙНЯТТЯ РІШЕНЬ ЯК КОМПОНЕНТИ ІНФОРМАЦІЙНОГО ЗАБЕЗПЕЧЕННЯ ОРГАНІЗАЦІї В УМОВАХ РИНКОВОЇ ЕКОНОМІКИ
}

\author{
Фісун К. А., д.е.н.,доцент, \\ Сиса А. Ю., студент-магістр (НАНГУ)
}

\begin{abstract}
У даній статті розглянуто підходи до використання систем підтримки прийняття рішень як компоненти інформаційного забезпечення організації в умовах ринкової економіки. В роботі виділений ряд проблем, вирішення яких можливо тільки при спільному використанні сучасних концептуальних положень теорії менеджменту та інформачійних технологій. Актуалізується задача розробки методичних основ побудови структур, щзо забезпечують рух потоків знань від сховищ даних через системи KDD до відповідних систем підтримки прийняття рішень в точках прийняття рішення. Окреслено коло ключових питань, які становлять основу підходу до дослідження $i$ побудови механізмів узгодженого розвитку інформаційних ресурсів та систем підтримки прийняття рімень, щуо трунтуються на цих інформаційних ресурсах.
\end{abstract}

Ключові слова: системи підтримки прийняття рінень, інформаційне забезпечення, управління, організація, ринкова економіка, інформаційні технологї̈.

\section{ПОДХОДЫ ИСПОЛЬЗОВАНИЯ СИСТЕМ ПОДДЕРЖКИ ПРИНЯТИЯ РЕШЕНИЙ КАК КОМПОНЕНТЫ ИНФОРМАЦИОННОГО ОБЕСПЕЧЕНИЯ ОРГАНИЗАЦИИ В УСЛОВИЯХ РЫНОЧНОЙ ЭКОНОМИКИ}

\author{
Фисун К. А., д.э.н., доцент, \\ Сыса А. Ю., студент-магистр (НАНГУ)
}

В данной статье рассмотрены подходы к использованию систем поддержки принятия решений как компоненты информаџионного обеспечения организаџии в условиях рыночной экономики. В работе выделен ряд проблем, решение которых

(C) Фісун К.A.,

Сиса А.Ю.
Вісник економіки транспорту і промисловості № 68, 2019 
возможно только при совместном использовании современных концептуальных положений теории менеджмента и информационных технологий. Актуализируется задача разработки методических основ построения структур, обеспечиваюших движение потоков знаний от хранилищ данных через системь $K D D$ в соответствующие систем поддержки принятия решений в точках принятие решения. Очерчен круг ключевых вопросов, составляюших основу подхода к исследованию и построения механизмов согласованного развития информационных ресурсов и систем поддержки принятия решений, основанные на этих информаџионных ресурсах.

Ключевые слова: системы поддержки принятия решений, информационное обеспечение, управление, организация, рыночная экономика, информационные технологии.

\title{
APPROACHES OF USE OF DECISION MAKING SUPPORT SYSTEMS AS COMPONENTS OF THE ORGANIZATION INFORMATION SUPPORT IN THE CONDITIONS OF THE MARKET ECONOMY
}

\author{
Fisun K., Associate Professor, Professor, \\ Sisa A. , Master's Degree (NANGU)
}

This article describes how to use decision support systems as components of an organization's information support in a market economy. The paper identifies a number of problems that can only be solved by sharing modern conceptual provisions of management theory and information technology.

The article focuses on the need to create methodological support for the organization of a multilevel system of information flows aimed at supporting decision-making at the enterprise with use. It is necessary to build the scheme of organization of information flows inside the enterprise so that at all stages of decision making the manager could receive information from all contours of information flows inside the enterprise, and not only from the corporate database of the enterprise information system. The combination of existing theoretical and decision-making methods with the correct organization of information is proposed, when different information flows for the manager are formed from the same data set as a result of systematization, allowing to concentrate on finding the optimal alternative for decision-making. Emphasis is placed on the need to create methods for constructing the communication and information structure of decision-making mechanisms. The paper indicates the need to explore the potential potential knowledge that can be gained, to combine them with the existing typology of methods and models, by determining which class of tasks they belong to. The problem of developing methodological foundations for building structures that provide the flow of knowledge flows from data warehouses through KDD systems to the relevant decision support systems at decision points is updated. The key issues that underlie the methodological approach to research and build mechanisms for coordinated development of information resources and decision support systems based on these information resources are outlined. Approaches to solving the presented problems are offered and the requirements for the developed methods are substantiated. Using a methodological approach, specific methods, models and procedures can be developed for different types of enterprises and DSS.

Keywords: decision support systems, information support, management, organization, market economy, information technology.

Вісник економіки транспорту і промисловості № 68, 2019 
Постановка проблеми. Процес прийняття управлінського рішення $\epsilon$ ключовою ланкою системи менеджменту підприємства. На стратегічному рівні управлінські рішення закладають основні напрямки розвитку підприємства в просторі і в часі. Однак сам процес і якість прийнятих рішень багато в чому залежать від умов функціонування господарюючих суб'єктів. Методологічне та методичне забезпечення ефективного використання інформаційних ресурсів в процесах прийняття рішень в багато визначає стратегії розвитку інформаційних ресурсів підприємства. Тим більше, що сучасний розвиток ринкової економіки має пряму залежність від процесу впровадження цифрових технологій. Реально цифровізація вимагає від сучасного підприємства провести повне та комплексному оснащення інформаційнокомунікаційними системами та технологіями, а також здійснити перегляд підходів до прийняття управлінських рішень

Аналіз останніх досліджень i публікацій. У роботах таких дослідників як Грабовський Є. М., Соколовський, С. А., Науменко М. О., Пушкарь А.I. та ін. [1-5] аналізуються питання забезпечення якості інформаційного підприємства. Аналіз специфіки організації інформаційних ресурсів i мультимедійних компонентів систем підтримки прийняття рішень найшов свого відображення в дослідженнях Грабовського Є. М., Мартінса П., Закарія М., Науменко М. О. та ін. [6-8]. Напрямки вдосконалення управління якістю продукції на основі використання інформаційних систем систематизовані у науковому дослідженні Науменко М.О. [9].

Виділення невирішених частин загальної проблеми. Однак, залишається невирішеним цілий ряд проблем, зокрема, побудова механізмів перетворення неформалізованого знання особи, яка приймає рішення (ОПР), фахівців підприємства, оптимального способу його узагальнення і застосування при прийнятті рішень в різних функціональних областях. Тому питання використання i перетворення інформаційних ресурсів підприємства в процесах прийняття рішення 3 використанням комп'ютерних систем підтримки прийняття рішень (СППР) вимагають подальших досліджень. Актуальність досліджуваних питань визначається тією об'єктивно важливою роллю, яку інформація відіграє в забезпеченні економічної діяльності.

Метою даної статті $є$ дослідження підходів використання систем підтримки прийняття рішень як компоненти інформаційного забезпечення організації в умовах ринкової економіки.

Викладення основного матеріалу дослідження. Слід зазначити, що, виконуючи функцію прийняття рішень, саме ОПР забезпечує коригування непередбачених відхилень від нормального функціонування системи i визначає послідовність, напрямки i кількість ресурсів, що виділяються для різних підсистем підприємства.

Оскільки мета СППР полягає в загальному випадку не в автоматизації процесу прийняття рішення, а в здійсненні кооперації між системою і людиною в процесі прийняття рішення, то вона повинна підтримувати інтуїцію, володіти вмінням розпізнавати двозначність i неповноту інформації, мати засоби для їх подолання.

Основні труднощі процесу прийняття рішення полягає в тому, що здібності індивідуума обмежені, коли потрібні різноманітна інформація і знання. Об'єднання декількох індивідуумів може допомогти, але проблеми координації i зв'язку можуть виникати i в групах. Комп'ютеризовані системи надають людям швидкий доступ i обробку великого кількості запасеної інформації. Комп'ютери можуть також покращувати координацію і зв'язок для роботи групи.

В області прийняття рішень в

Вісник економіки транспорту і промисловості № 68, 2019 
системі управління підприємством може бути виділений ряд проблем, вирішення яких, на думку авторів, можливо тільки при спільному використанні сучасних концептуальних положень теорії менеджменту та інформаційних технологій.

Перша проблема - створення методичного забезпечення організації багаторівневої системи інформаційних потоків спрямованих на підтримку прийняття рішень на підприємстві 3 використанням СППР.

Сутність запропонованого підходу до вирішення даної проблеми полягає в наступному. Існуючі на сьогоднішній день СППР припускають використання інформації з різних видів баз даних і баз знань 3 наступною іiі обробкою i трансформацією ОПР. Однак насправді необхідна інформація може міститися в інформаційних потоках всередині підприємства [10].

Якщо припустити наявність кількох контурів таких потоків, то перший 3 них буде пов'язаний безпосередньо 3 рухом інформації з баз даних до виконавців, які виробляють ii первинну обробку, другий контур включає в себе безпосередньо ОПР, а третій - СППР.

Таким чином, для того, щоб система прийняття рішень на підприємстві працювала найбільш ефективно необхідно побудувати схему інформаційних потоків всередині організації, виділивши ті зони, де інформація з'являється i ті, де вона поглинається ОПР. Обидві ці зони повинні бути об'єднані інформаційними потоками, тоді при русі по ієрархічних рівнях системи управління ОПР можуть перетворюватися в постачальників інформації.

Необхідно побудувати схеми організації інформаційних потоків всередині підприємства таким чином, щоб на всіх етапах прийняття рішення: формування переліку альтернатив; формування переліку можливих станів зовнішнього середовища; опис та оцінка результатів реалізації альтернатив в конкретних умовах зовнішнього середовища, ОПР могли отримувати інформацію з усіх контурів інформаційних потоків всередині підприємства, а не тільки з корпоративної БД інформаційної системи підприємства.

Отже, саме ОПР повинні формулювати вимоги до інформації: яка інформація необхідна, від кого, в які терміни і в якій формі. Тоді отримані відомості можуть бути відразу ж використані на етапах прийняття рішення i не потребують додаткової обробки, що істотно заощаджує час на прийняття рішення [11].

Другою проблемою $є$ поєднання існуючих теоретичних методів і моделей прийняття рішення 3 правильною організацією інформації, коли 3 одного і того ж масиву даних в результаті систематизації формуються різні за своєю структурою інформаційні потоки для ОПР, що дозволяють зосередити увагу на оптимальної альтернативи при прийнятті рішення. Йдеться про те, що для різних працівників і різних цілей одну i ту ж інформацію необхідно організувати порізному.

Третя проблема - створення методів побудови комунікаційно-інформаційної структури механізмів прийняття рішень. Такі структури повинні будуватися на основі розробки переліків базових рольових дій забезпечення процесу підготовки i прийняття рішення, прив'язаних до конкретних організаційних структур i функціональних областях підприємства. В результаті використання такого класу методів можуть бути сформульовані вимоги i побудовані технології організації потоків неформалізованих знань між окремими суб'єктами управління - особами які приймають рішення, функціональними фахівцями, виконавцями. Таке неформалізоване знання являє собою їх особистісну трактування і бачення того, як певну частину даних 3 корпоративної бази може відображати нові можливості,

Вісник економіки транспорту і промисловості № 68, 2019 
загрози, вказувати на сильні і слабкі сторони альтернатив або сформованих проблемних ситуацій.

Четвертою проблемою є організація знань, яка породжена появою комп'ютерних систем KDD, що дозволяють проводити пошук знань в базах даних. Поряд 3 наявністю накопичених на підприємствах ретроспективних масивів даних це робить можливим отримувати 3 них різного роду інформацію і приймати на iii основі нові, нестандартні рішення. Тому необхідно досліджувати можливі потенційні знання, які можуть бути отримані, поєднати їх 3 існуючою типологією методів і моделей, встановивши до якого класу задач вони відносяться. У зв'язку з цими виникає задача розробки методичних основ побудови структур, що забезпечують рух потоків знань від сховищ даних через системи KDD до відповідних СППР в точках прийняття рішення.

Основні етапи робіт по створенню інформаційної інфраструктури СППР на основі пропонованого авторами підходу полягає в наступному. підприємства.

1. Аналіз бізнес-процесів i даних процесів:

Вибір підходу до аналізу бізнес-

- опис бізнес-процесів:

- первинний аналіз бізнес-подій (транзакцій).

2. Побудова багаторівневої моделі інформаційних потоків підприємства на основі обраного підходу до їх організації (потоки з баз даних, від ОПР, фахівців, виконавців; потоки формалізованих i неформалізованих знань; потоки, які використовуються в одному підрозділі або функціональної області і в декількох областях).

3. Аналіз даних, що використовуються підприємством. Збір інформації про використовувані зовнішніх даних i ïx джерелах в типових ситуаціях прийняття рішень.
Збір відомостей від ОПР про необхідні форматах даних, періодичності та формою їх надходження («які дані мені потрібні», «які дані я можу надати»).

Створення рольових моделей подання інформації (склад i форма відображуваних даних в інформаційних потоках):

- розподіл рольових функцій користувачів системи;

- доступ до даних, обсяг даних необхідний для аналізу, джерела даних;

- систематизація інформаційних потоків на основі принципу ключових подій i формування на цій основі характеристик системи - вимірювання даних, основні звіти, послідовність перетворення аналітичної інформації.

4. Формування схеми взаємодії між транзакційною системою і системою СППР на підприємстві на основі використання побудованої організаційної схеми інформаційних потоків.

Таким чином, інформаційне забезпечення організації в умовах ринкової економіки, за умов, коли цифрові технології проникли у всі сфери діяльності та внесли принципові зміни у організаційну поведінку підприємства, є тим чинником, що має безпосередній вплив на забезпечення ефективності іiі розвитку. Зокрема, організація цифрової інтеграції $є$ тим чинником, який має безпосередній вплив на формування механізмів узгодженого розвитку інформаційних ресурсів та систем підтримки прийняття рішень в сучасних умовах.

Висновок.

Рішення сформульованих в статті ключових проблеми становить основу підходу до дослідження i побудови механізмів узгодженого розвитку інформаційних ресурсів та СППР, що грунтуються на інформаційних ресурсах.

Запропоновано підходи до вирішення представлених проблем i обгрунтовані вимоги до розроблюваних методів. На основі запропонованих підходів можуть бути розроблені конкретні

Вісник економіки транспорту і промисловості № 68, 2019 
методи, моделі та процедури для різних типів підприємств та СППР.

\section{ПЕРЕЛІК ВИКОРИСТАНИХ ДЖЕРЕЛ}

1. Hrabovskyi Y. Methods of Assessment and Diagnosis of the Quality of Knowledge in E-Learning / Y. Hrabovskyi // Journal of Communication and Computer. 2015. - № 12. - P. 286-296.

2. Науменко М.О. Підходи до забезпечення стратегічного управління підприємств в умовах нестійкого середовища / М.О. Науменко, О.С. Рига // Вісник економіки транспорту i промисловості. - 2018. - Вип. 63. - С. 216223.

3. Соколовський С. А. Аналіз особливостей управління інформаційними потоками логістичних процесів підрозділів Національної гвардії України / С. А. Соколовський, М.О. Науменко // ScienceRise. - 2018. - № 2. - C. 19-21.

4. $\mathrm{Hu}$ C. AHP and CA Based Evaluation of Website Information Service Quality: An Empirical Study on High-Tech Industry Information Center Web Portals / C.Hu, Z Yang, G.Mingjing // Journal Service Science \& Management. - 2009. - № 3. - P. 168-180 DOI: https://doi.org/10.4236/jssm.2 009.23020

5. Пушкарь А. И. Стратегическое управление развитием электронного бизнеса и информационных ресурсов предприятия. / А. И. Пушкарь, Е. Н. Грабовский, Е. В. Пономаренко. Х.: Изд-во ХНЭУ, 2005. 480 с.

6. Грабовський Є. М. Проектування інтелектуального користувацького інтерфейсу систем підтримки електронного навчання / С. М. Грабовський // Scientific Journal «ScienceRise». - 2018. - № 11(52). C. 36-39

7. Martins P. A Web-based Tool for Business Process Improvement / P.Martins, M.Zacarias // International Journal of Web Portals. - 2017. - Volume 9. - Issue 1. - P. 68 $84 \quad$ DOI: https://doi.org/10.4018 /IJWP.2017070104
8. Грабовський Є. М. Аналіз використання мультимедійних компонентів в сучасних технологіях мобільного навчання / С. М. Грабовський // Scientific Journal «ScienceRise».- 2019 - № 4(57). C. $46-50$

9. Науменко М. О. Вдосконалення управління якістю продукції високотехнологічних підприємств / М. О. Науменко // Вісник економіки транспорту і промисловості. - 2018. Вип.№ 62. - С. 335-342.

10. Каличева Н. С. Роль інформаційних технологій у розвитку підприємств транспорту / Каличева Н. Є. // Проблеми міжнародних транспортних коридорів та корпоративної логістики: тези доповідей за матеріалами X Міжнар. наук.прак. конф. (5-7 червня 2014 р, м. Харків). Харків: УкрДАЗТ. - 2014. - С. 100-101.

11. Каличева Н. Є. Проблеми та перспективи впровадження інформаційних технологій у вітчизняній транспортній сфері. Сучасна економіка: актуальні проблеми та перспективи розвитку: колективна монографія /за заг. редакцією дра екон. наук, професора В. В. Прохорової. Харків: «НТМТ», - 2014. - С. 73-78.

\section{REFERENCES}

1. Hrabovskyi Y. (2015). Methods of Assessment and Diagnosis of Knowledge Quality in E-Learning. Journal of Communication and Computer. No. 12, pp. 286-296.

2. Naumenko M. O., Riga O. S. (2018). Pidxody` do zabezpechennya strategichnogo upravlinnya pidpry`yemstv $\mathrm{v}$ umovax nestijkogo seredovy`shha [Approaches to providing strategic management of enterprises in an environment of unstable environment] Bulletin of the Economics of Transport and Industry of the UGCC. No. 63, pp. 216-223.

3. Sokolovskyi S. A., Naumenko N. A. (2018). Analiz osobly`vostej upravlinnya informacijny`my` potokamy` logisty`chny`x procesiv pidrozdiliv Nacional'noyi gvardiyi Ukrayiny. [Analysis of peculiarities of

Вісник економіки транспорту і промисловості № 68, 2019 
management of information flows of logistic processes of units of the National Guard of Ukraine]. ScienceRise. No 2, pp. 19-21.

4. Hu C., Yang Z, Mingjing G. AHP and CA Based Evaluation of Website Information Service Quality: An Empirical Study on High-Tech Industry Information Center Web Portals//Journal Service Science \& Management. 2009. № 3. P. 168-180 DOI: https://doi.org/10.4236/jssm.2009.23020.

5. Pushkar A.I., Grabovsky E.N., Ponomarenko E.V. (2005). Strategy`cheskoe upravleny`e razvy`ty`em эlektronnogo by`znesa y` y`nformacy`onnix resursov predpry yaty`ya [Strategic Management of the Development of E-Business and Information Resources of Enterprise]/ Kharkiv: KhNPU Publishing House, 480 p. (in Ukrainian).

6. Grabovsky E. M. (2018). Proektuvannya intelektual'nogo kory`stuvacz`kogo interfejsu sy`stem pidtry`mky` elektronnogo navchannya [Designing the Intelligent User Interface of ELearning Support Systems]. Scientific Journal «ScienceRise». No. 11 (52), pp. 36-39

7. Martins P., Zacarias M. A (20170Web-based Tool for Business Process Improvement//International Journal of Web Portals. Vol. 9. Issue 1, pp. 68 - 84 DOI: https://doi.org/10.4018/IJWP.2017070104.

8. Grabovsky E. M. (2019). Analiz vy`kory`stannya mul ty`medijny`x komponentiv $\mathrm{v}$ suchasny` $\mathrm{x}$ texnologiyax mobil nogo navchannya. [Analysis of the use of multimedia components in modern technologies of mobile learning]. Scientific Journal "ScienceRise". No. 4 (57), pp. 46-50.

$$
\text { 9. Naumenko M. O. (2018). }
$$

Vdoskonalennya upravlinnya yakistyu produkciyi vy`sokotexnologichny`x pidpry yemstv. [Improvement of product quality management of high-tech enterprises. Bulletin of the Economics of Transport and Industry of the UGCC. No. 62, pp. 335 - 342.

10. Kalicheva N. E. (2014). Rol informacijny` $x$ texnologij $u$ rozvy`tku pidpry yemstv transportu. [The role of information technology in the development of transport enterprises]. Problems of International Transport Corridors and Corporate Logistics: Abstracts on X International. Research Assistant Conf. (June 5-7, 2014, Kharkiv). Kharkiv: UkrDAZT, pp. 100-101.

11. Kalicheva N.E. (2014). Problemy` ta perspekty`vy vprovadzhennya informacijny`x texnologij u vitchy`znyanij transportnij sferi. [Problems and prospects of introduction of information technologies in the domestic transport sphere]. Suchasna ekonomika: aktual'ni problemy ta perspekty`vy' rozvy`tku: kolekty`vna monografiya. [Modern Economics: Current Issues and Prospects for Development: A Collective Monograph]. Kharkiv: NTMT, pp. 73-78. 